hospital admissions, had higher activity impairment and reported worse quality of life and sleep, whilst asymptomatic patients utilised the least resources and reported the best quality of life and sleep. The remaining groups suffered similar levels of burden.

Conclusions In this analysis, patients experiencing morning, daytime and night-time symptoms have the worst PROs and more disease burden. Clearer recognition of symptom burden and an individualised treatment approach may be warranted for these patients.

\begin{tabular}{|c|c|c|c|c|c|c|}
\hline $\begin{array}{l}\text { Outcomes } \\
\text { (Mean, S. } \\
\text { D.) }\end{array}$ & $\begin{array}{l}\text { None } \\
(\mathrm{n}=2060)\end{array}$ & $\begin{array}{l}\text { D only } \\
(n=1274)\end{array}$ & $\begin{array}{l}\text { M/D only } \\
(n=1378)\end{array}$ & $\begin{array}{l}\text { D/N only } \\
(n=477)\end{array}$ & $\begin{array}{l}M, N \text { or } \\
M / N \text { only } \\
(n=345)\end{array}$ & $\begin{array}{l}M / D / N \\
(n=2651)\end{array}$ \\
\hline $\begin{array}{l}\text { PCP } \\
\text { consultations }\end{array}$ & $2.8(2.9)$ & $3.1(3.0)$ & $3.0(3.0)$ & $3.8(3.2)$ & $3.1(3.1)$ & $4.4(4.5)$ \\
\hline $\begin{array}{l}\text { Specialist } \\
\text { consultations }\end{array}$ & $1.7(1.8)$ & $2.3(2.2)$ & $2.4(2.2)$ & $2.1(2.0)$ & $1.7(1.9)$ & $2.8(2.8)$ \\
\hline ER visits & $0.0(0.3)$ & $0.1(0.4)$ & $0.1(0.4)$ & $0.2(0.5)$ & $0.1(0.4)$ & $0.3(0.6)$ \\
\hline $\begin{array}{l}\text { Hospital } \\
\text { admissions }\end{array}$ & $0.0(0.2)$ & $0.1(0.5)$ & $0.2(0.6)$ & $0.2(0.5)$ & $0.1(0.5)$ & $0.5(1.0)$ \\
\hline $\begin{array}{l}\% \text { activity } \\
\text { impairment }\end{array}$ & $24.6(20.0)$ & $36.8(20.1)$ & $41.0(22.0)$ & $\begin{array}{l}45.0 \\
(19.4)\end{array}$ & $\begin{array}{l}33.7 \\
(22.2)\end{array}$ & $56.4(23.2)$ \\
\hline EQ-5D-3L & $0.89(0.18)$ & $0.85(0.19)$ & $0.81(0.22)$ & $\begin{array}{l}0.80 \\
(0.19)\end{array}$ & $\begin{array}{l}0.86 \\
(0.17)\end{array}$ & $0.69(0.28)$ \\
\hline EQ-VAS & $72.7(15.0)$ & $66.7(14.8)$ & $63.7(15.0)$ & $\begin{array}{l}62.9 \\
(16.1)\end{array}$ & $\begin{array}{l}68.6 \\
(13.9)\end{array}$ & 56.3 (17.6) \\
\hline CAT & $14.2(7.4)$ & $18.4(7.1)$ & $20.2(6.9)$ & $21.5(6.1)$ & $18.9(7.1)$ & $25.7(6.6)$ \\
\hline $\begin{array}{l}\text { JSEQ } \\
\text { Impact on } \\
\text { Sleep, } \mathrm{n}(\%)\end{array}$ & $2.4(2.9)$ & $3.6(3.3)$ & $4.3(3.9)$ & $5.6(3.4)$ & $4.4(3.5)$ & $8.3(4.8)$ \\
\hline None & $485(42.1)$ & $212(32.9)$ & $189(26.2)$ & $11(4.5)$ & $42(20.1)$ & $60(4.2)$ \\
\hline Low & $512(44.5)$ & $295(45.7)$ & $347(48.1)$ & $90(37.0)$ & $86(41.1)$ & $364(25.2)$ \\
\hline Medium & $121(10.5)$ & $103(16.0)$ & $142(19.7)$ & $\begin{array}{l}105 \\
(43.2)\end{array}$ & $50(23.9)$ & $557(38.6)$ \\
\hline High & $30(2.6)$ & $33(5.1)$ & $39(5.4)$ & $36(14.8)$ & $22(10.5)$ & $367(25.5)$ \\
\hline Constant & $3(0.3)$ & $2(0.3)$ & $4(0.6)$ & $1(0.4)$ & $9(4.3)$ & $94(6.5)$ \\
\hline
\end{tabular}

PCP - Primary care physician; ER - Emergency Room; M - Morning; D - Daytime; N Night time; CAT - COPD Assessment Test; JSEQ - Jenkins Sleep Evaluation Questionnaire

\section{P216 ASSOCIATIONS BETWEEN THE PSYCHOLOGICAL HEALTH OF PATIENTS AND THEIR INFORMAL CARERS IN ADVANCED COPD: WHAT ARE THE RISK FACTORS FOR ANXIETY AND DEPRESSION IN PATIENTS, CARERS AND PATIENT-CARER DYADS?}

${ }^{1} \mathrm{EZ} \mathrm{Mi},{ }^{1} \mathrm{EZ} \mathrm{Mi},{ }^{2} \mathrm{~S}$ Mendonca, ${ }^{2} \mathrm{AC}$ Gardener, ${ }^{2} \mathrm{MC}$ Farquhar. ${ }^{1}$ School of Clinical Medicine, University of Cambridge, Cambridge, UK; ${ }^{2}$ Department of Public Health and Primary Care, University of Cambridge, Institute of Public Health, Cambridge, UK

\subsection{6/thoraxjnl-2016-209333.359}

Introduction Anxiety and depression (AD) are highly prevalent in patients with advanced COPD and their informal carers, and are associated with lower quality of life and increased healthcare use. Previous studies have postulated risk factors for patient $\mathrm{AD}$ in COPD (including dyspnoea, poor functional status and poor selfmanagement) and carer AD (including female gender, insufficient support and high subjective symptom burden). However, little is known about the association between patient and carer $\mathrm{AD}$. We aimed to determine this and factors associated with patient, carer and dyad AD.
Methods Prospective mixed-method interviews with a population-based cohort of 109 pairs of well-characterised advanced COPD patients and their carers. Clinical anxiety and depression (defined as Hospital Anxiety and Depression Scale [HADS] anxiety or depression score $>11$ ) were identified and a dichotomous 'psychological morbidity' (PM) variable created (HADS score $>11$ for either anxiety or depression) due to small sample size. MannWhitney $\mathrm{U}$ tests and multivariate logistic regression identified factors associated with patient $(n=39)$ or carer $(n=30)$ PM.

Results Prevalence of anxiety and depression was 31.2\% and $15.6 \%$ in patients and $26.6 \%$ and $11 \%$ in carers respectively. In univariate analysis, patient and carer PM were significantly associated with each other $(\mathrm{p}=0.005)$, with odds ratio $3.388(95 \%$ CI: 1.414-8.118), and mainly disease-related variables and carer characteristics (including poor coping and unmet support needs), respectively. No demographic factors were significantly associated with patient PM but female gender was associated with carer PM. Table 1 shows the results of multivariate analysis. Finally, dyad PM was associated with male patients/female carers, living apart, parent-child relationship, and more exacerbations.

Conclusions For patients, more exacerbations may indicate disease progression resulting in anxiety, fatigue may limit activity leading to social isolation and depression, and poor self-management may increase symptom burden leading to AD. Patient PM could lead to carer PM by increasing carer burden and impairing intra-dyad communication. Our study, with the strength of a prospective approach and recruitment from primary care, highlights the need to assess $\mathrm{AD}$ in carers of COPD patients (particularly with $\mathrm{AD}$ ), to prevent it with more information and support for carers, and for interventions targeting the dyad.

\section{P217 IMPROVING CARE AND SUPPORT IN ADVANCED COPD - SIX RECOMMENDATIONS FROM THE POPULATION- BASED LIVING WITH BREATHLESSNESS STUDY}

${ }^{1} \mathrm{MC}$ Farquhar, ${ }^{1} \mathrm{G}$ Ewing, ${ }^{2} \mathrm{P}$ White, ${ }^{3} \mathrm{P}$ Burge, ${ }^{4} \mathrm{R}$ Mahadeva, ${ }^{1} \mathrm{AC}$ Gardener, ${ }^{1} \mathrm{C}$ Moore, ${ }^{5} \mathrm{~S}$ Howson, ${ }^{1} \mathrm{~S}$ Booth, ${ }^{3} \mathrm{C}$ Saunders, ${ }^{3} \mathrm{~T}$ Ling. ${ }^{1}$ University of Cambridge, Cambridge, UK; ${ }^{2}$ King's College London, London, UK; ${ }^{3}$ RAND Europe, Cambridge, UK; ${ }^{4}$ Cambridge University Hospitals NHS Foundation Trust, Cambridge, UK; ${ }^{5}$ Cambridge and Peterborough Foundation Trust, Cambridge, UK

\subsection{6/thoraxjnl-2016-209333.360}

Introduction Chronic obstructive pulmonary disease (COPD) is a chronic life-limiting condition with high symptom-burden and carer-burden. National guidance on end of life care calls for quality care for patients with any condition, yet we rely on frameworks developed for cancer with its largely predictable trajectory. Aim To develop evidence-based recommendations to inform a new framework to improve care and support of patients living with advanced COPD and their informal carers.

Methods The Living with Breathlessness Study was a multiplecomponent, population-based, mixed-method longitudinal, multiple-perspective research programme to identify new evidence on health and social care needs and preferences of patients with advanced COPD and their carers. It followed more than 500 patients and carers for up to 18 -months through interview and survey methods. Qualitative data on barriers and facilitators to meeting needs were collected from clinicians. Programme-wide evidence was synthesised to identify recommendations. Stakeholder views were then collected through a workshop and online survey.

Results Six inter-related recommendations emerged, linked by the concept of proactive person-centred care: (1) Stop the 
Abstract P216 Table 1 Multivariate analysis of predictive factors significantly associated in univariate analysis with patient or carer PM

\begin{tabular}{|c|c|c|c|c|}
\hline & Patient PM cases $(n=39)$ & Patient PM non-cases $(n=70)$ & Odds ratio $(95 \% \mathrm{Cl})$ & Significance \\
\hline \multicolumn{5}{|l|}{ Carer PM cases, n (\%) } \\
\hline Y & $17(15.6)$ & $13(11.9)$ & $3.667(0.916-14.680)$ & 0.066 \\
\hline $\mathrm{N}$ & $22(20.2)$ & $57(52.3)$ & & \\
\hline \multicolumn{5}{|l|}{ Patient gender, $\mathrm{n}(\%)$} \\
\hline M & $24(22.0)$ & $42(38.5)$ & $0.728(0.194-2.740)$ & 0.639 \\
\hline $\mathrm{F}$ & $15(13.8)$ & $28(25.7)$ & & \\
\hline No. of exacerbations at home, median (IQR) & $3.5(2-6)$ & $2(0-3)$ & $1.313(1.006-1.713)$ & $0.045^{*}$ \\
\hline CRQ dyspnoea score, median (IQR) & $1.8(1.6-2.6)$ & $2.8(1.8-4)$ & $1.227(0.628-2.398)$ & 0.549 \\
\hline CRQ fatigue score, median (IQR) & $2.5(2-3)$ & $3.75(3-4.5)$ & $0.392(0.173-0.889)$ & $0.025^{*}$ \\
\hline CRQ mastery score, median (IQR) & $3.25(2.25-3.75)$ & $4.75(4.25-5.5)$ & $0.264(0.129-0.539)$ & $0.000^{*}$ \\
\hline \multirow[t]{2}{*}{ No. of patient physical co-morbidities, median (IQR) } & $4(3-6)$ & $4(2-5)$ & $0.832(0.577-1.201)$ & 0.326 \\
\hline & Carer PM cases $(n=30)$ & Carer PM non-cases $(n=79)$ & Odds ratio $(95 \% \mathrm{Cl})$ & Significance \\
\hline \multicolumn{5}{|l|}{ Patient PM cases, n (\%) } \\
\hline Y & $17(15.6)$ & $22(20.2)$ & $3.869(1.070-13.990)$ & $0.039^{*}$ \\
\hline $\mathrm{N}$ & $13(11.9)$ & $57(52.3)$ & & \\
\hline \multicolumn{5}{|l|}{ Carer gender, $\mathrm{n}(\%)$} \\
\hline M & $2(1.8)$ & $29(26.6)$ & $6.180(1.167-32.712)$ & $0.032^{*}$ \\
\hline $\mathrm{F}$ & $28(25.7)$ & $50(45.9)$ & & \\
\hline \multicolumn{5}{|l|}{ Lives with patient, $\mathrm{n}(\%)$} \\
\hline Y & $24(22.4)$ & $71(66.4)$ & $1.883(0.438-8.100)$ & 0.395 \\
\hline $\mathrm{N}$ & $6(5.6)$ & $6(5.6)$ & & \\
\hline Duration of caring in years, median (IQR) & $3.5(2-12)$ & $7(4-13)$ & $0.964(0.903-1.030)$ & 0.278 \\
\hline Hours of caring, median (IQR) ${ }^{\mathrm{a}}$ & $3(2-3.5)$ & $3(2-4)$ & $0.859(0.420-1.755)$ & 0.676 \\
\hline No. of exacerbations at home, median (IQR) & $3(1.5-5.5)$ & $2(0-3.75)$ & $1.048(0.880-1.247)$ & 0.599 \\
\hline No. of carer physical co-morbidities, median (IQR) & $1(1-2)$ & $1(0-2)$ & $1.184(0.769-1.825)$ & 0.443 \\
\hline
\end{tabular}

(a) $1=<1 \mathrm{~h} /$ week, $2=1-19 \mathrm{~h} /$ week, $3=20-49 \mathrm{~h} /$ week, $4=>50 \mathrm{~h} /$ week.

continual focus on the challenge of prognosis and unpredictability of trajectories as barriers to meeting needs, (2) Change targets to incentivise person-centred care within existing services, (3) Enable identification and response to patient support needs (through evidence-based tools and approaches), (4) Identify and support patients' informal carers (through evidence-based tools and approaches), (5) Identify and respond to psychological morbidity in patients and informal carers identify and respond to psychological morbidity, (6) Change societal attitudes and understandings of COPD, breathlessness, palliative care and informal carer support. The recommendations are underpinned by action points to enable delivery. The recommendations garnered significant support from stakeholders, with caution regarding ease of implementation which varied by recommendation.

Conclusion These six inter-related recommendations, and supporting action points, could inform a new framework for care and support in advanced COPD likely to have resonance for those living with other advanced non-malignant long term conditions, and for clinicians striving to support them.

\section{P218 THE DEVELOPMENT AND PSYCHOMETRIC VALIDATION OF THE EARLY MORNING SYMPTOMS OF COPD INSTRUMENT (EMSCI)}

${ }^{1} \mathrm{~A}$ Hareendran, ${ }^{1} \mathrm{E}$ Zaiser, ${ }^{2} \mathrm{~B}$ Make, ${ }^{3} \mathrm{E}$ Garcia Gil. ${ }^{1}$ Evidera, London, UK; ${ }^{2}$ National Jewish Health, Denver, USA; ${ }^{3}$ Astra-Zeneca, London, UK

\subsection{6/thoraxjnl-2016-209333.361}

Introduction In patients with Chronic Obstructive Pulmonary Disease (COPD), symptoms in the early morning have been reported as being the most troublesome and can negatively impact quality of life. This abstract summarises the development and psychometric testing of the Early Morning Symptoms of COPD Instrument (EMSCI) designed to collect data to evaluate COPD patients' experiences early in the morning.

Methods Following a literature review and clinical expert interviews, four focus groups were conducted to identify initial concepts and develop draft items for the EMSCI. One-on-one cognitive debriefing interviews were conducted with 10 COPD patients to confirm item readability, and comprehensiveness. Data from a clinical trial [AUGMENT] in COPD patients $(\mathrm{N}=1663)$ was used for item analyses to inform item-reduction and scoring; and to evaluate psychometric properties. Test-retest reliability was assessed using intra-class coefficient (ICC). Correlations with baseline assessments including the SGRQ, E-RS, and FEV1 were used to evaluate concurrent validity.

Results Focus group participants $(n=27$, mean age $=68.1 \mathrm{y}$ ) reported mucus/phlegm (80\%), shortness of breath $(52 \%)$, coughing (48\%), tightness in chest (24\%), wheezing $(8 \%)$ and chest congestion $(8 \%)$ as the most common early morning symptoms. Limitations to activities and rescue medication use in the early morning were reported by $56 \%$ and $24 \%$ respectively. Cognitive interviews of early versions of the EMSCI suggested the items were comprehensive, relevant and interpreted as intended. Analyses of EMSCI data collected in the Phase 3 trial confirmed a one-factor structure for the symptom severity items. Reliability was confirmed for the 6-item symptom severity (ICC $=0.84$ ), overall symptom severity $(\mathrm{ICC}=0.84)$, activity limitation $(\mathrm{ICC}=0.85)$, and rescue medication $(\mathrm{ICC}=0.62)$ scores. Concurrent validity (Table 1 ) was supported by positive correlations with both the SGRQ and the E-RS scores. 